\title{
NUTRITION OF GRAZING SHEEP
}

L. R. WALLACE, Senior Principal Scientific Officer, Ruakura Animal Research Station, Hamilton

During recent years quite a lot of information has been accumulated which shows the way in which sheep respond to different levels of feeding imposed for short periods at different times of the year. As a result, we have a very clear idea of which are the more, and which are the less important periods from the point of view of animal performance. Although there is still a very great need for long-term studies on a complete farm basis, designed to ascertain the grazing management systems that will give the best over-all results on different types of farm in different localities, the work already done has, at least, established the main principles upon which grazing management must be based if good results are to be obtained.

In this talk I intend first to review briefly some of the evidence relating to the nutrition of sheep at particular stages, and then to discuss some rather broader issues. From the point of view of the breeding flock the year can be conveniently divided into three periods: from weaning till tupping, from tupping till lambing, and from lambing onwards.

\section{Froui Weaning until Tupping}

Most farmers are well acquainted with the practice of flushing and with the advantages which can be expected from it. Essentially the practice consists of feeding ewes so that they are definitely improving in condition for about three weeks before the rams are introduced, and also for the first three or four weeks of the mating period. The purpose of this is to stimulate the ovaries to ripen and shed an increased number of eggs at the time of mating and so improve the lambing percentage. The value of the practice has been thoroughly tested in numerous trials, some overseas and others in New Zealand, and we now know fairly well the sort of result that can be expected. Flushing does not, as a rule, bring ewes on heat any earlier or reduce the percentage of ewes failing to lamb, and it may somewhat increase the lambing spread. Its most important effect is to increase substantially the proportion of twins born. If mature 5- and 6-year-old Romney ewes are properly flushed on pasture, about half of those that lamb should produce either twins or triplets, so that, allowing for a normal percentage of dry ewes and average ewe deaths and lamb losses, 
it is reasonable to expect to dock about 125 lambs from each 100 ewes put to the ram. This applies to well-grown ewes run on typical fat lamb country.

In discussing the practice of flushing, it is often emphasised that the ewes should be in vigorous store condition at the time that flushing is begun, it being held that ewes in such condition respond much better to an improved level of nutrition than do those that are either very thin or over-fat. Indeed the opinion that overfatness tends to reduce fertility is quite widely held by farmers, and often ewes are deliberately grazed very hard for a period after weaning with a view to reducing their condition in preparation for tupping.

There is, however, quite a body of evidence to indicate that high condition does not in itself reduce reproductive performance. A Romney flock of approximately 400 mixed age ewes has been maintained at Ruakura for the last 10 years, and each year the ewes have been weighed about the middle of February, approximately a fortnight before the rams are turned in, and the way in which the lambing percentage has followed the liveweight has been most interesting. In the years when the ewes were heavy just before tupping, comparatively high lambing percentages have been obtained, while in seasons when the ewes were light, lambing percentages have been relatively low. These results suggest that it may be very poor practice indeed to overdo the process of starving the condition off ewes after weaning.

A small trial was carried out at Ruakura this year to obtain further information on this point. The lambs belonging to a flock of 6-year-old ewes were weaned in mid-December, and the ewes immediately divided into three similar groups. During the next two months the ewes of Group I were grazed over the best pasture that could be provided, whereas Groups II and III were kept on poorer feed so that the animals steadily lost weight, one group being much more severely treated than the other. As a result, by mid-February, the animals in Group I were exceedingly fat, whereas those in Group II were in moderate condition and those in Group III rather thin. From mid-February onwards the ewes of all three groups were run together on the best feed that could be provided, and three weeks later, at the end of the first week of March, the rams were introduced. A sample of the ewes from each group were killed during the tupping period to determine the average number of eggs being produced, and the balance of the animals was carried on and lambed together. It turned out that the ewes which were allowed to become excessively fat before mating produced rather more eggs and had a higher lambing percentage than those from either of the other two groups. The number of dry ewes was greatest in the thinnest group and least 
in the fattest group, the ewes which failed to lamb being in the main animals which were rather thin at the time of tupping.

It would probably be unwise to pay too much attention to the results from this one small experiment, and I should emphasise that in the trial just described the fat ewes were well fed from the time of weaning right through to tupping. Very different results might have been obtained had these animals been allowed to become excessively fat by mid-February and then been allowed to suffer a check during the critical six-week period starting three weeks before the introduction of the rams. In the present state of knowledge it would seem wise to ensure that feed is conserved for flushing purposes, even if this means having to do the ewes fairly hard after weaning. There does not appear to be any good reason for grazing the ewes any harder than is necessary to ensure that sufficient feed is saved for the lambs and cattle and for flushing purposes. A prolonged period of semi-starvation after weaning can quite seriously reduce the fleece weight, for the rate of wool growth is affected not only during the period of poor feeding; when poorly fed animals in low condition are changed to a good diet they take time to recover. In the trial at Ruakura this year ewes that were fed so that they gained $10 \mathrm{lb}$ liveweight between mid-December and mid-February, grew between mid-December and mid-March $.7 \mathrm{lb}$ more wool than did ewes which lost $10 \mathrm{lb}$ during the same two-month period, and over $1 \mathrm{lb}$ more than ewes which lost $20 \mathrm{lb}$ during the period of restricted feeding.

While on the subject of flushing, I should perhaps mention that on the basis of the trials that have been conducted at Ruakura, it appears that ewes should be flushed for at least three weeks before mating if optimum results are to be obtained. Naturally, it is important that the flock should be well fed throughout the period during which the ewes are being tupped in appreciable numbers, which usually means for three or four weeks after the rams are put out. The ewes employed in this trial at Ruakura were in good store condition at the time of commencement of flushing.

It is often stated that the beneficial effects of flushing do not appear to be related to the use of any particular feeds, and it is certainly true that good results have been achieved in many ways; by flushing on crops, by changing from poor to good pastures, and by feeding cereals. The main consideration is that the ewes should actually make substantial liveweight gains and put on condition rapidly over the flushing period. Nevertheless, it does seem that under certain circumstances the nature of the feed can be of considerable importance. For instance, Professor Coop and co-workers at Lincoln College have recently reported the results 
of a two-year trial in which lucerne and grass were compared as flushing feeds. In the first year the ewes flushed on lucerne produced 10 per cent fewer twins and 15 per cent more barren ewes than those flushed on grass. In the second season 600 Border Leicester-Corriedale ewes were employed, half flushed on lucerne and half on ryegrass and white clover. Despite the fact that liveweight changes were approximately the same in both groups, those flushed on lucerne produced 7 per cent fewer twins, 2 per cent more barren ewes, and their mean lambing date was delayed by five days. The reason for the comparatively poor results with lucerne is not at present known.

\section{From Tupping to Lambing}

When a ewe is successfully mated, the fertilised egg begins to develop during the three to four days which it spends travelling down the fine tube which leads from the ovary into the womb. It increases very little if at all in size during the first 10 days, and even at the end of the first month of pregnancy the embryo weighs only about $1 / 60 \mathrm{oz}$, being then about the size of a pea. At the end of the second month it weighs about $2 \mathrm{oz}$ and at the end of the third between 1 and $2 \mathrm{lb}$. By the end of the fourth month the foetus is usually still not quite half grown and weighs between 4 and $5 \mathrm{lb}$. The rate of weight increase is thus at a maximum during the final month before birth, and it is therefore not surprising that this is the critical period as far as the nutrition of the ewe is concerned.

The feeding of ewes during pregnancy can be conveniently discussed under the following heads: the effects upon birth weight, upon ewe and lamb mortality, upon the rate of growth of the lambs after birth, and upon the amount of wool grown.

When I was working at Cambridge in England with Dr Hammond after the war I carried out feeding trials which showed that the level of nutrition of the ewe during the first three months of pregnancy had little effect upon the growth of the developing lamb, whereas very poor feeding during the later stages had a most pronounced effect on birth weight. The relative unimportance of feeding in early pregnancy has also been shown by feeding trials conducted in Scotland in which raising the level of feeding of ewes during the last months was as effective as a high level of feeding throughout pregnancy in producing lambs of good birth weight.

The extent to which the birth weight of lambs is affected depends, of course, on the degree of under-nutrition imposed in late pregnancy, and it is much more difficult to affect the birth weight of single lambs than twins. Results from a grazing trial that was repeated over three successive years at Ruakura illustrate this very well. Each year a group of Romney ewes was mated to Southdown 
rams, and the animals run together as a single flock up till five weeks before the first lambs were due to be born. The flock was then divided into three groups. The first was grazed on abundant pasture and the ewes gained on average about $5 \mathrm{lb}$ a week. The second group were fed upon a somewhat lower plane and they gained about $23 \mathrm{lb}$ a week. The third group were grazed very hard indeed and did not gain weight, but actually lost condition. The lambs were weighed within 24 hours of birth, and the ewes and lambs from the three groups were all run together from the time of lambing onwards. The average birth weights of the lambs are shown in Table 1.

TABLE l-Effect of Level of Feeding of Ewes Before Lambing on Birth $\begin{array}{crccc} & \text { Weight of Lambs } & & \\ \text { Level of Feeding } & \text { High } & \text { Medium } & \text { Low } \\ \text { Av. birth weight of singles (lb) } & & 10.3 & 10.2 & 9.6 \\ \text { Av. birth weight of twins (lb) } & \ldots . .- & 8.8 & 8.4 & 7.3\end{array}$

On average the single lambs from the medium plane ewes were almost as heavy as those from the high plane ewes. The low plane treatment did, however, reduce the birth weight of the single lambs by about $0.7 \mathrm{lb}$. In the case of the twins the effect upon birth weight was graded according to the level of feeding, with an average difference of approximately $13 \mathrm{lb}$ between the extreme high and low plane treatments.

At first sight it might be argued that at least as far as the singles are concerned the average differences in birth weight are so small as to be of no practical importance. However, average values can be very misleading. The small average difference of $1 / 10 \mathrm{lb}$ shown between the birth weights of the single lambs from the high and medium plane ewes was, in fact, almost entirely due to quite a large effect on the biggest lambs, particularly on the biggest of the ram lambs. The 10 per cent heaviest ram lambs from the high plane ewes were on average $1 \mathrm{lb}$ heavier than the corresponding ram lambs from the medium plane ewes; and with big single lambs weighing about $13 \mathrm{lb}$ an extra pound can make all the difference between a relatively easy birth and an extremely difficult one. Ewe and lamb mortality, at lambing itself and during the first week after birth, is probably the greatest single source of economic loss in sheep in New Zealand, and the birth weight of the lambs governs the magnitude of this loss to a considerable extent. Among single lambs losses tend to be concentrated among the very heavy lambs. For instance, when the single lambs born over the three years in the grazing experiment just described were grouped into. birth weight classes and the mortality within each birth weight class ascertained, it was found that the death rate at birth and during the fii-st week was only 3.3 per cent for lambs 
of about average size weighing 9 to $11 \mathrm{lb}$, but over 30 per cent for the heaviest lambs weighing $13 \mathrm{lb}$ or more and for the lightest weighing $7 \mathrm{lb}$ or less.

Birth weight is also very important with twins, losses in this case being concentrated among the lighter twin sets. Over the three years at Ruakura the death rate among twin lambs at birth and during the first week was only 7.3 per cent for those weighing more than $7 \mathrm{lb}$, but 28 per cent among those weighing $7 \mathrm{lb}$ or less.

From the foregoing it will be clear that from the point of view of lamb mortality a very high level of feeding before lambing should be avoided, for it is apt to result in a proportion of very big single lambs which the ewes have difficulty in delivering, and among which a high death rate must in consequence be expected. On the other hand, a very low level of nutrition must also be avoided, for this will result in an unduly high proportion of lightweight twins, which tend to be born weak and which are apt to die through failure to get a drink, from exposure, or from mismothering during the first few days after birth. During each of the three years at Ruakura lamb losses were lowest among the lambs from the ewes which had been fed only moderately well during the pre-lambing period. It is, perhaps, worth recording that although this intermediate level of feeding reduced birth weight of single lambs by an average of only $1 / 10 \mathrm{lb}$, it was effective in reducing the proportion of single lambs weighing more than $11 \mathrm{lb}$ from 13 per cent to 5 per cent.

Let us consider now the effect of the level of feeding during pregnancy upon the growth of lambs after birth. Quite a lot of information is available on this point from experiments in which ewes differently fed before lambing have been grazed together from the time of lambing onwards. In the Ruakura studies already referred to the lambs from the three groups of ewes all grew equally well. At Lincoln College Professor Coop also has found that a high level of nutrition during pregnancy, which increased birth weight by about $0.5 \mathrm{lb}$, had but little if any influence on the rate of growth and the weaning weight of the lambs, irrespective of the level of nutrition after lambing. In attempting to explain this, Professor Coop has suggested that provided the level of feeding before lambing is not too low, the ewes poorly fed are still reasonably strong and vigorous at lambing, and after lambing are hungry and probably eat more than ewes that have fed at a high level previously, which tends to stimulate milk production. Whatever the true explanation, I think it can be taken as established that differences in plane of nutrition before lambing which produce only small differences in birth weight usually have little 
or no effect on the subsequent growth rate of either single or twin lambs.

Wool growth is, of course, affected by the level of feeding during pregnancy. In the trials carried out at Ruakura over three seasons, the average Aeece weight of the ewes that were moderately well fed before lambing was only about a $1 / 10 \mathrm{lb}$ less than that for the high plane ewes, but the very low level of feeding reduced fleece weights by an average of $0.6 \mathrm{lb}$. In the trials carried out by Professor Coop at Lincoln College, 14 weeks of differential feeding before lambing produced differences in fleece weight which averaged about $1 \frac{1}{4} \mathrm{lb}$.

Pregnancy toxaemia disease can cause very heavy losses. It is a condition which is usually associated with a sudden check in nutrition near lambing. It occurs mainly in ewes with single lambs. It is uncommon in ewes that are well fed or on a slightly rising plane of nutrition over the last few weeks of pregnancy, but ewes carrying twins and in fat condition from good feeding in early pregnancy are certainly not immune. Indeed many people hold the view that such fat animals are the most susceptible to a sudden food shortage before lambing.

Bearing trouble can be extremely troublesome during the last few weeks before lambing, and 1 do not think that there is any doubt that this complaint can be seriously aggravated by libera grazing on lush pastures during the pre-lambing and lambing period.

\section{From Lambing 0 nwards}

There is quite a body of experimental evidence which emphasises the importance of level of feeding after lambing. In studies at Ruakura where ewes have been treated alike up to lambing, but thereafter stocked at different rates on similar pastures, the more heavily stocked animals have produced the lighter lambs at weaning. At Lincoln College Professor Coop has produced liveweight differences at weaning amounting to about $10 \mathrm{lb}$ for singles and 10 to $15 \mathrm{lb}$ for twins simply by varying the level of feeding after lambing.

During the first month or six weeks of its life the lamb is almost entirely dependent for its growth upon its mother's milk, and each additional $4 \mathrm{lb}$ of milk that a lamb drinks during the first month of its life will increase its liveweight when a month old by about $1 \mathrm{lb}$. From six weeks of age onwards, however, the lamb becomes increasingly dependent upon the pasture it eats, so that grazing management must be directed to having really high quality feed available from this time onwards. Usually by the end of the third month of lactation, milk production has fallen to quite a low level, and if feed is becoming short there is much to be said for the 
practice of early weaning, particularly under hill country conditions where the objective is not the production of fat lambs and where a large number will have to be carried through the summer drought period,

On fat lamb farms it is probably unwise to consider weaning until the first draught is taken. If feed is abundant, the lambs remaining after the first are sent away will probably do better if left with their mother for a further period, but if feed is short, they should be weaned so that the ewes do not compete for the available feed and the best can be offered to the lambs.

At the Ruakura Hill Country Station Mr Clarke has found that the greatest advantage of early weaning lies in the flexibility that it confers on stock management. There, ewes which were shorn and whose lambs were weaned in late November have been used most effectively to control bracken fern still in the vulnerable early frond stage, and this method of fern control has proved cheaper and more effective than any other method of grazing management with other classes of stock.

So far I have been concerned mainly with the manner in which sheep respond to different levels of nutrition imposed over particular periods and with the general levels of nutrition that must be provided if the best results are to be obtained from the individual animals. However, few sheepmen are in the happy position of being able to farm just for the interest and pleasure of doing so. Most are obliged to pay quite close attention to the important question of financial returns. Thus in discussing the question of nutrition of sheep at pasture one is really concerned not so much with those methods of feeding and management that are best for the animals, but rather with those that are likely to prove most profitable to the men who own them.

The sheepfarmers' income is derived in part from the sale of wool and in part from the sale of stock. His returns are determined not merely by the average productivity of his animals, but also and very greatly, by the total numbers of these that his farm can be made to carry. A high rate of stocking is indeed probably the most important factor of all in achieving a high output of meat and wool per acre, and there is little doubt that it is usually well worth while to make some sacrifice in the level of production per animal to obtain a really high carrying capacity. It is usually much more important to ensure that the stocking rate is sufficiently high to utilise completely all the feed grown than it is to strive for maximum production per animal.

At Ruakura itself Miss Walker has shown this to be true for fat lamb production, while Mr Clarke and his colleagues have shown it to be the case on breeding country at the Ruakura Hill 
Country Station. There, trials are being carried out to compare the production obtained from a flock well managed throughout the year and always fully fed with that from a similarly bred flock farmed under a system of heavy stocking at all times. Results to date show that the heavy stocking system has reduced wool production per ewe by about 15 per cent, the lambing percentage by up to 10 per cent, and the weight of the lambs at weaning by about 10 to 12 per cent. The information obtained does not yet permit accurate conversion of these differences to a per acre basis, but Mr Clarke's carefully considered estimate of the relative stocking rates under the two systems is about three for the heavily stocked animals to two for the others, and there is no doubt that the heavily stocked system would yield the greater return on a farm basis.

In New Zealand, pasture forms virtually the sole diet of sheep, and the only control that the farmer can exercise over the nutrition of his flock at different times is through grazing management. Pasture does not grow uniformly throughout the year, and the real essence of a successful pasture management programme is the adoption of a system that over a period of years will result in an over-all improvement in pasture productivity and at the same time ensure that the essential feed requirements of the animals are adequately met, particularly during critical periods.

We have already seen that as far as the breeding flock is concerned the critical periods are fairly well defined. They are in late summer and early autumn just before and during the tupping period, in late winter during the last stages of pregnancy, and in early spring shortly after lambing. For the lambs the whole of the lactation period and indeed the first nine months of life is, in fact, a critical time, but after the onset of the spring flush the problem is seldom that of a feed shortage, but rather one of maintaining herbage quality.

The importance of a high stocking rate has already been stressed, and clearly it is under a farming system aimed at the fullest possible utilisation of all feed grown that the method of feed utilisation is most important. This is particularly true of the periods of low pasture production. Although, as far as I am aware, no critical experiments have been carried out to test the practice, there would seem to be a very good case for the spelling of a proportion of the farm in late April and May when the rate of pasture growth is still reasonably high and when the ewes can be grazed reasonably hard without disadvantage, so that a reserve of feed is built up for use during the poor pasture production period in late winter and early spring when animal needs are considerably higher. 
The most effective method of utilisation of this saved feed can pose quite a difficult problem. It can be rationed off very economically by an on-and-off system of grazing, but pastures that have been allowed to grow too long tend to deteriorate in quality and after grazing may be rather open and low in clover content. In my view the autumn spelled pastures should not be allowed to grow too long and should, in the main, be grazed off by ewes before lambing, or by those with young lambs at foot. As soon as the earliest born lambs get to the stage where they begin to eat pasture in any quantity they are best transferred to and lightly stocked on the paddocks that are just freshening after having been kept under close grazing through the autumn and early winter. At this stage the later lambing ewes and those with young lambs can be concentrated to thoroughly clean out the autumn saved paddocks, which, if grazed in this way, should, as the spring advances, freshen nicely to provide feed of good quality by the time this is required by the later born lambs. In my experience the quality of the feed present on autumn saved paddocks that have been partially grazed off is quite suitable for unlambed or freshly lambed ewes, but is not good enough for lambs a month or six weeks old.

On many farms it is usual to rotationally graze through the autumn and winter and set stock from lambing time onwards. Unless serious damage from trampling and pugging occurs, the practice of rotational grazing through the winter has much to commend it. Stock can be compelled to utilise fully all feed present on areas that may have been previously neglected or differentially grazed under set-stocking conditions. Such differential grazing is, of course, particularly prone to occur on paddocks of broken contour. The rotational grazing system, too, is one that even during a period of feed shortage inevitably results in the accumulation ahead of the flock of a reserve of feed, and the size of this reserve can be regulated by the speed of rotation. Moreover, as lambing approaches, it is quite an advantage not to have to search the whole farm each day for ewes that are cast or in trouble in other ways.

In general, I believe that just before entering, and also during, a period of feed abundance, it is sound practice to set-stock, particularly if the contour is such that surplus feed cannot be conserved in the form of hay or silage. During flush periods the problem seldom is one of feed shortage, but of maintaining feed quality and of delaying as long as possible the stage when feed quality deteriorates through the uncontrolled growth and premature seeding of pastures. This is more easily achieved under a set stocking system. When entering a period of abundance a re- 
serve of feed ahead of the flock is merely an embarrassment. Also there seems no good reason why the animals should not be given full opportunity to exercise what preferences they may have in the matter of herbage selection. Most of the trials that have been carried out to contrast the effects of the set stocking and rotational grazing systems after lambing have shown rather better lamb growth under set stocking. At Ruakura under intensive fat lambing conditions, Lambourne compared set stocking and rotational grazing at three different levels of stocking-four, six, and eight ewes per acre. At the lower rates the rotational system resulted in rather poorer lamb growth, but at the higher rate it was definitely superior. In no case was there any substantial difference in ewe wool production or liveweight gain.

The only long-term grazing management study that has been carried out in New Zealand is that- conducted by Suckling at the Te Awa hill research area, There he has compared the set stocking and rotational grazing systems on a complete annual basis over a number of seasons. Set stocking gave much superior production in terms of meat and wool. Suckling found that the rotationally grazed ewes became so accustomed to shifts, that they were in a constant state of unrest and ready to move at the slightest disturbance. As a result over the lambing period mismothering was a constant worry, ewes being apt to desert a newly born lamb, a weaker twin, or a sleeping lamb.

In conclusion I should like to say that in my opinion there is a great need for further long-term investigations to compare the production that can be obtained from various systems of grazing management and particularly to contrast results from systems of feed utilisation specifically designed to ensure that the known requirements of the flock at critical stages are, in fact, adequately met, with those from uncontrolled systems such as set stocking which have given surprisingly good results on many occasions. Many of the trials that have been reported can be criticised on the grounds that they have been concerned with comparing various routine methods of stock movement rather than with grazing management systems intelligently aimed at fitting the variable supply of nutrients from pasture to the variable but known nutritional needs of animals.

\section{DISCUSSION}

Q. (J. 0. H. Tripp): Has the "creep method" been used for feeding lambs in New Zealand? It has been used in England with quite good results.

A. It is under test at Ruakura at present. It is in its first season and so far no differences have been observed. 
C. E. Iversen: Prof. Coop has it under trial at Lincoln and has not yet seen any benefit. In a poor season the situation could be quite different.

Q. (C. P. Tebb): Would Dr Wallace enlarge on the profitability of high stocking rate? Examining various sets of figures from the Waikato area 1 have noticed that farms with high rates of stocking have a poorer net income than those with medium rates of stocking.

A. My comments were based on results of work done by Prof. Coop and Miss Walker. In Miss Walker's experiment the higher stocking rate should lower individual lamb weight gains, but give much higher gains per acre. Obviously it is possible to stock too heavily, but in my experience there tends to be far more understocking than overstocking.

Q. (Mrs Cooper, Gisborne): In a drought is it economic to feed concentrates prior to flushing to keep the lambing percentage up?

A. The cost of that would be approximately 5/- per sheep per month. The answer cannot be definite. In a severe drought it would probably be payable.

Q. (N. A. Cullen): Invermay has conducted trials over three seasons and has not found lambing percentage affected by plane of nutrition prior to flushing. Does Dr Wallace consider that sheep which had been on a high nutrition plane throughout summer would respond as well to flushing as those that had been on a low plane?

A. At Ruakura there were three groups of ewes, high, medium and low condition prior to flushing. When the groups were mobbed together for flushing, the high condition ewes actually lost weight but at the end of three weeks all groups went ahead together. However, the high plane group gave a 20 per cent better lambing percentage than the low plane ewes. The fat ewes also had a much better ovulation.

Q. (Pemberton): In spite of drought last year Canterbury had good lambs where fresh water was available. Does $\mathrm{Dr}$ Wallace not consider that short feed of good quality being utilised by heavy concentrations of stock quickly rotated is important to lamb thrift?

A. For pasture improvement it is certainly important to have high stock numbers for the fertility cycle. You cannot, however, compare Canterbury and Waikato conditions. The quality of the feed must be considered. If the D.M. of herbage falls below 12 per cent the dairy cow cannot ingest sufficient for adequate nutrition. The same applies to sheep. Last year was very growthy in the Waikato and lambs did poorly. It would not have helped at all to increase stock concentrations.

Q. (D. A. Campbell): Would Dr Wallace advocate maximum stocking in this East Coast area with its very variable rainfall.

A. One must certainly exercise caution with this class of country. Where there is no flat land for making hay or silage, it may be worthwhile buying hay for use in poor years. But stocking should not be set at the minimum capacity of a drought year.

Comment (R. H. Bevin): The Australian example of going from 70 to 150 million sheep was partly built around the question of fodder conservation. Not many years ago Canterbury's carrying capacity was merely reflecting the minimum seasons. Improvement since has been a reflection on ability to overcome seasonal shortages. Our next 10 million sheep in New Zealand will be a difficult process and will depend upon new management policies.

Reeves, Gisborne: This East Coast area has a safety valve in times of drought, that is, the ability to sell large numbers of stock to wetter areas, such as the Waikato. This to a large extent overcomes the need here for feed conservation. 